\title{
PREVALENCE OF ANEMIA IN PREGNANT WOMEN ATTENDING A TERTIARY LEVEL HOSPITAL IN WESTERN REGION, NEPAL
}

\author{
Nabin Rayamajhi ${ }^{1}$, Satyendra Kumar Mishra ${ }^{2}$, Narayan Gautam ${ }^{3}$, Nilesh Raj Doshi ${ }^{4}$
}

\section{ABSTRACT}

\section{INTRODUCTION:}

In South Asian Region, the prevalence of anemia among pregnant women has been estimated to be $75 \%$ which is highest in the world. Hence, this study was drafted to evaluate the prevalence of anemia in pregnant women in western part of Nepal

\section{MATERIALS AND METHODS:}

It was a hospital based cross-sectional study. A total of 200 pregnant ladies aged 15-45 years giving consent for the study were included and their detailed medical history, clinical examination and lab investigations focusing on hematological parameters were documented. Data were entered in excel sheet and analysed by SPSS (17.0).

\section{RESULTS:}

The prevalence of anemia in pregnant women was $48 \%$ with increased prevalence as the pregnancy proceeds and reaching its highest during third trimester of pregnancy. Young adults with age ranging from 15-30 years had highest prevalence of anemia. Mild anemia (Hb: 9-10.9 g/dl) was the commonest entity.

\section{CONCLUSION:}

With this high prevalence, screening for anemia during pregnancy should be done. Moreover, exogenous supplementation of iron capsules or diet rich in iron can be advised to those anaemic pregnant women.

\section{KEYWORDS:}

Anemia, Hemoglobin, Pregnancy, Trimester

1. Lab Technologist, Central Laboratory, Universal College of Medical Sciences, Bhairahawa, Nepal

2. Lecturer, Department of Pathology, Universal College of Medical Sciences, Bhairahawa, Nepal

3. Associate Professor, Department of Biochemistry, Universal College of Medical Sciences, Bhairahawa, Nepal

4. Professor, Department of Obstetrics and Gynaecology, Universal College of Medical Sciences, Bhairahawa, Nepal

\author{
For correspondence: \\ Nabin Rayamajhi \\ Lab Technologist, Central Laboratory \\ Universal College of Medical Sciences, \\ Bhairahawa, Nepal \\ E-mail: rayamajhinab@gmail.com
}




\section{INTRODUCTION:}

Anemia is a major public health problem especially among poorer segment of the population in developing countries. Anemia is the commonest nutritional problem worldwide with its highest prevalence among young children and pregnant women. ${ }^{1}$ On an average, $56 \%$ of pregnant women of developing regions of the world are anemic with a range of $35 \%$ to $100 \%$ among various regions of the world. ${ }^{2}$ In South Asian Region, the prevalence of anemia among pregnant women has been estimated to be $75 \%$ which is highest in the world.

Anemia in pregnancy is an important public health problem worldwide. WHO estimates that more than half of pregnant women in the World have a hemoglobin level indicative of anemia $(<11.0 \mathrm{~g} / \mathrm{dl})$, the prevalence may however be as high as $56 \%$ to $61 \%$ in developing countries. ${ }^{4}$ Women often become anemic during pregnancy because the demand for iron and other vitamins is increased due to physiological burden of pregnancy. The inability to meet the required level for these substances either as a result of dietary deficiencies or infection gives rise to anemia. ${ }^{5}$ The degree of anemia graduated for severity of anemia in pregnancy as per WHO includes; 10.0 $10.9 \mathrm{~g} / \mathrm{dl}$ (mild anemia), 7-9.9 g/dl (moderate anemia) and $<7$ $\mathrm{g} / \mathrm{dl}$ (severe anemia). ${ }^{6}$ In pregnancy, anemia has a significant impact on the health of the fetus as well as that of the mother. $20 \%$ of maternal death in Africa has been attributed to anemia. ${ }^{7}$ Fetuses are at risk of preterm deliveries, low birth weight, morbidity and parental mortality due to the impairment of oxygen delivery to placenta and fetus.

Pregnancy is a state of hemodilution in which there is an intravascular volume expansion. Initially the increase in plasma volume is larger than the rise in red cell volume and this result in a drop in hemoglobin. Severe anemia less than 8 $\mathrm{gm} \%$ is associated with the birth of low birth weight babies and a major factor influencing hemoglobin concentration in pregnancy is expansion of plasma volume. ${ }^{9}$ Anemia, even when mild to moderate affects the sense of well-being resulting in fatigue, stress and reduced work productivity. ${ }^{\circ}$ During labour, women with severe anemia are less able to endure moderate blood loss and as a consequence are at a higher risk of requiring a blood transfusion during delivery. ${ }^{11}$ Iron deficiency and consequent anemia during pregnancy could be associated with severe complications like increased risks of maternal mortality and morbidity, premature delivery, and low birth weight. Thus, routine screening tests for anemia are recommended in pregnant women. ${ }^{12}$ On the other hand, the World Health Organization (WHO) has reported the prevalence of anemia in pregnant women of Eastern Mediterranean countries to be $44.2 \%{ }^{13}$ Iron Deficiency Anemia (IDA) is known to be an important factor in maternal death, poor cognitive development of children and decreased work capacity of mother. ${ }^{14}$ There has been association of anemia with adverse pregnancy outcomes, higher incidence of preterm and low birth weight deliveries. ${ }^{15}$ So the study was conducted to find the prevalence of anemia in pregnant women attending ante-natal check-up clinic at a tertiary level hospital in western region, Nepal. Similarly, prevalence of anemia in different trimesters of pregnancies, in different age groups of pregnancies as well as severity of anemia by quantifying level of hemoglobin were also assessed.

\section{MATERIALS AND METHODS:}

This is a hospital based cross-sectional study conducted at ante-natal check-up clinic at Universal College of Medical Sciences and Teaching Hospital, Ranigaon, Bhairahawa, Nepal from June 2015 - October 2015. Two hundred samples were collected by simple random sampling technique with inclusion of all pregnant women in the age group 15-45 years. Pregnant women under medication for any pathological condition associated with hematological disorders were excluded in this study.

The degree for severity of anemia in pregnancy was graduated as per WHO criteria:

- Mild anemia: $10.0-10.9 \mathrm{~g} / \mathrm{dl}$

- Moderate anemia: $7.0-9.9 \mathrm{~g} / \mathrm{dl}$

- Severe anemia: $<7.0 \mathrm{~g} / \mathrm{dl}$

Hemoglobin estimation was done by Cyanmethemoglobin method. Data were analysed via SPSS (17.0). Data were expressed in frequency or percentage.

\section{RESULTS}

Out of total 200 pregnant women, there were 96 pregnant women with anemia. Hence, the prevalence of anemia in pregnant women in our study was $48 \%$.

The incidence of mild anemia was observed in third trimester with frequency $16 \%$, moderate anemia with $4 \%$ and severe anemia with $0.5 \%$. (Table 1 )

Maximum incidence of 18\% was observed in age group 21-25 in mild anemia, where as moderate anemia was with age group $26-30$ years in $3.5 \%$ and severe anemia was $0.5 \%$ in age group 21.25 years. (Table 2 )

Maximum frequency of anemia $41 \%$ was observed to be mild followed by $65 . \%$ moderate and than $0.5 \%$ severe. (Table 3 )

Table No. 1: Prevalence of Anemia in various Age groups

\begin{tabular}{|c|c|c|c|}
\hline $\begin{array}{l}\text { Age Group } \\
\text { (years) } \\
15-20\end{array}$ & $\begin{array}{c}\text { Mild Anemia } \\
\text { Hb10-10.9 g/dl } \\
15(7.5 \%)\end{array}$ & $\begin{array}{c}\text { Moderate Anemia } \\
\mathbf{H b}<7-9.9 \mathrm{~g} / \mathrm{dl} \\
2(1 \%)\end{array}$ & $\begin{array}{c}\text { Severe Anemia } \\
\mathbf{H b}<7.0 \mathbf{g} / \mathbf{d l} \\
0(0 \%)\end{array}$ \\
\hline $21-25$ & $36(18 \%)$ & $4(2 \%)$ & $1(0.5 \%)$ \\
\hline $26-30$ & $26(13 \%)$ & $7(3.5 \%)$ & $0(0 \%)$ \\
\hline $31-35$ & $4(2 \%)$ & $0(0 \%)$ & $0(0 \%)$ \\
\hline $36-40$ & $1(0.5 \%)$ & $0(0 \%)$ & $0(0 \%)$ \\
\hline Total & $82(41 \%)$ & $13(6.5 \%)$ & $1(0.5 \%)$ \\
\hline
\end{tabular}

Table 2: Prevalence of Anemia in different Trimester

\begin{tabular}{|l|c|c|c|}
\hline Trimester & $\begin{array}{c}\text { Mild Anemia } \\
\mathbf{H b 1 0 - 1 0 . 9} \mathbf{g} / \mathbf{d l}\end{array}$ & $\begin{array}{c}\text { Moderate Anemia } \\
\mathbf{H b}<\mathbf{7 - 9 . 9} \mathbf{g} / \mathbf{d l}\end{array}$ & $\begin{array}{c}\text { Severe Anemia } \\
\mathbf{H b}<\mathbf{7 . 0} \mathbf{~ g} / \mathbf{d l}\end{array}$ \\
\hline First Trimester & $22(11 \%)$ & $0(0 \%)$ & $0(0 \%)$ \\
\hline Second Trimester & $28(14 \%)$ & $5(2.5 \%)$ & $0(0 \%)$ \\
\hline Third Trimester & $32(16 \%)$ & $8(4 \%)$ & $1(0.5 \%)$ \\
\hline Total & $82(41 \%)$ & $13(6.5 \%)$ & $1(0.5 \%)$ \\
\hline
\end{tabular}


Table 3: Frequency of severity of Anemia

\begin{tabular}{|l|c|c|}
\hline Severity of Anemia & Frequency & Percentage \\
\hline Mild Anemia & 82 & $41 \%$ \\
\hline Moderate Anemia & 13 & $6.5 \%$ \\
\hline Severe Anemia & 1 & $0.5 \%$ \\
\hline Total & 96 & $48 \%$ \\
\hline
\end{tabular}

\section{DISCUSSION:}

In our study, the prevalence of anemia in pregnant women was $48 \%$ which is similar to the study conducted by Sinha AK et al. ${ }^{16}$ However, it is less than other studies conducted at different parts of the country including the study conducted at Kathmandu, Dharan by different authors. The reason may include preparation of food in iron utensils or food rich in iron content were used.

Age group 21-25 years in our study group had highest prevalence of anemia (20.5\%) followed by sequential elder groups of age. Hence, our study confirmed that younger age groups had higher prevalence of anemia compared to elder age groups which is also supported by study from Sinha AK et al. ${ }^{16}$ Younger pregnant women are at higher risk for anemia due to poor iron absorption.

In our study, the prevalence of anemia was higher in third trimester $(20.5 \%)$ followed by second trimester $(16.5 \%)$ and least in first trimester (11\%). Physiological hemo-dilution is more during third trimester followed by second trimester and least during first trimester and this can explain the above mentioned findings in our study.

Most of the pregnant women in our study had mild anemia $(41 \%)$ followed by moderate and severe anemia respectively. This is in agreement with the study done by Sinha AK et al. ${ }^{16}$ This preponderance of less severe (mild anemia) in our study can be linked to good maternal care, better nutrition, lower incidence of worm infestation or parasite infection.

\section{CONCLUSION:}

With this high prevalance, screening for anemia during pregnancy should be done. Moreover, exogenous supplementation of iron capsules or diet rich in iron can be advised to those anaemic pregnant women.

\section{REFERENCES:}

1. Centers for Disease Control and Prevention. Recommendations to prevent and control iron deficiency in the United States. Morbidity and Mortality Weekly Report. 1998; 47(RR-3):1-36.

2 World Health Organization. The prevalence of anaemia in women: a tabulation of available information. $2 n d \mathrm{Ed}$. Geneva: 1992.

3 World Health Organization, UNICEF \& UNU Iron Deficiency: Indicators for Assessment and Strategies for Prevention World Health Organization. Geneva: 1998.
4 World Health Organization. Prevention and Management of Severe Anemia in Pregnancy. Report of a technical working group. Geneva: WHL/FHE/MSM/93:3, 1994.

5 Van den Broek, N. The Cytology of Anemia in Pregnancy in West Africa Tropical Doctor 1996;26:57.

6 World Health Organization. Preventing and Controlling Iron Deficiency Anemia through Primary Health Care. WHO Publications. Aug, 1989.

7 Harrison, KA. Maternal Mortality and Anemia in Pregnancy. W. Afr. Med.J. 1975; 23:2731.

8 De-Mayer, EM. Preventing and Controlling Iron Deficiency Anemia through Primary Health Care. Geneva. WHO,1989.

9 Steer PJ. Maternal haemoglobin concentration and birth weight. Am JClin Nutr. 2000;71:1258-8

10 Haas JD, Brownlie TT. Iron deficiency and reduced work capacity: a critical review of the research to determine a causal relationship. JNutr 2001; 131: 676S-688S

11 Zucker JR, Lackritz EM, Ruebush TK, et al. Anaemia, blood transfusion practices, HIV and mortality among women of reproductiveage in western Kenya. Trans $R$ Soc Trop Med Hyg 1994; $8: 173$

12 Malee M. Anemia in Pregnancy. Obstet Gynecol. 2008;112(1):201-7.

13 De-Benoist, B.; McLean, E.; Egli, I \& Cogswell, M. Worldwide prevalence of anemia 1993-2005, WHO. Global Database on Anemia. Geneva. World Health Organization. P: 21,2008.

14 Hadary Jennifer, Cohenand Jere D. Haas. "Hemoglobin correction factors for estimating the prevalence of iron deficiency anemia in pregnant women residing at high altitudes in Bolivia." Rev Panam Salud Publica/Pan Am J Public Health 1999.

15 Government of India (sample registration system). Maternal mortality in India: 1997-2003, Trends, causes and risk factors. Register General India, New Delhi in collaboration with Centre for Global Health Research University of Toranto, Canada.

16 Sinha AK, Dubey RK, Padmavathi P, Neupane YR, Archana J, Gautam N. Prevalence of anemia amongst reproductive age group women of south western Nepal. The Journal of Obstetrics \& Gynecology and Reproductive Biology 2013;114:170-74. 